\title{
Piloting a Savings-Led Microfinance Intervention with Women Engaging in Sex Work in Mongolia: Further Innovation for HIV Risk Reduction
}

\author{
Laura Cordisco Tsai*, ${ }^{*}$, Susan S. Witte ${ }^{1}$, Toivgoo Aira ${ }^{2}$, Batsukh Altantsetseg ${ }^{2}$ and Marion Riedel ${ }^{3}$ \\ ${ }^{I}$ Global Health Research Center of Central Asia and Social Intervention Group, Columbia University, New York, \\ USA \\ ${ }^{2}$ Wellspring NGO and Global Health Research Center of Central Asia, Ulaanbaatar, Mongolia \\ ${ }^{3}$ Columbia University School of Social Work, New York, USA
}

\begin{abstract}
This paper describes a pilot study testing the feasibility of an innovative savings-led microfinance intervention in increasing the economic empowerment and reducing the sexual risk behavior of women engaging in sex work in Mongolia. Women's economic vulnerability may increase their risk for HIV by compromising their ability to negotiate safer sex with partners and heightening the likelihood they will exchange sex for survival. Microfinance has been considered a potentially powerful structural HIV prevention strategy with women conducting sex work, as diversification of income sources may increase women's capacity to negotiate safer transactional sex. With 50\% of all reported female HIV cases in Mongolia detected among women engaging in sex work, direct prevention intervention with women conducting sex work represents an opportunity to prevent a potentially rapid increase in HIV infection in urban Mongolia. The piloted intervention consisted of a matched savings program in which matched savings could be used for business development or vocational education, combined with financial literacy and business development training for women engaging in sex work. Results of the pilot demonstrate participants' increased confidence in their ability to manage finances, greater hope for pursuing vocational goals, moderate knowledge gains regarding financial literacy, and an initial transition from sex work to alternative income generation for five out of nine participants. The pilot findings highlight the potential for such an intervention and the need for a clinical trial testing the efficacy of savings-led microfinance programs in reducing HIV risk for women engaging in sex work in Mongolia.
\end{abstract}

Keywords: HIV, Financial education, Business development.

\section{INTRODUCTION}

Women who engage in sexual behavior as a means of economic support have a compromised ability to be concerned about long-term health consequences [1]. Since women often lack economic independence to a greater extent than men, they may be less able to negotiate safer sex with partners, less able to leave abusive relationships (and therefore at greater risk of HIV), and more likely to exchange sex for survival, all of which can increase women's risk for HIV [2-4]. Individuals who exchange sex for money may have limited power to negotiate safe sex practices with clients due to the higher premium gained through unprotected sex, the price of condoms, and urgent need for income in times of crisis or immediate need [5-7]. Given the connection between poverty, gender inequality and HIV risk, structural interventions addressing the economic, social and environmental determinants of risk are critical for HIV prevention efforts [1, 6, 8-11]. Although the structural factors impacting HIV risk are widely acknowledged, research evaluating structural HIV prevention interventions is rare [9, 11, 12]. Broader and more innovative HIV prevention interventions

*Address correspondence to this author at the Global Health Research Center of Central Asia and Social Intervention Group, Columbia University, New York, USA; Tel: 1-917-848-5984; Fax: 1-212-832-2215;

E-mail: lac2128@columbia.edu targeting the social and environmental structures that influence risk are needed $[1,11,12]$. This paper describes the implementation and results of the pilot test of Undarga, an innovative savings-led microfinance program sensitive to the unique needs of Mongolian women engaging in sex work.

\section{Microfinance in HIV Risk Reduction Efforts}

Microfinance has been considered a potentially powerful structural intervention tool to prevent HIV/AIDS [7, 13, 14], including among women engaged in sex work $[1,5,6,15-$ 17]. For example, Intervention for Microfinance and Gender Equity (IMAGE), a combined microfinance and HIV education intervention for women in South Africa, resulted in significant reductions in levels of unprotected sex for intervention participants and increased confidence in negotiating safer sex practices $[15,16]$. Strengthening STD/HIV Control Project (SHCP), a peer-mediated HIV education and microfinance intervention with women engaging in sex work in Kenya, demonstrated significant departures from sex work and an increase in reported condom use, especially for women above the age of 24 [5]. One limitation, however, in existing microfinance interventions is that many such programs have focused on micro-credit, which is financially riskier for vulnerable populations than other forms of microfinance since a borrower's savings are sometimes taken as collateral, interest rates are often high, and the financial pressure to avoid default can increase risk behavior if micro- 
enterprise start-up does not succeed as hoped [7, 18]. Borrowers may use money from other sources to repay their loans if their enterprise is not successful [19-21], which may be particularly hazardous for women already engaging in high-risk transactional sex. Micro-credit programs can also at times leave participants worse off financially due to overindebtedness [7, 21, 22]. In contrast, savings-led programs may provide a safer introduction to microfinance since they foster asset development and financial independence without the financial risks associated with debt $[18,22]$. To the researchers' knowledge, no studies have been conducted to date regarding the impact of a savings intervention on HIV risk for women engaged in sex work.

Mongolia is an ideal setting for testing the potential impact of a savings-led microfinance program as an HIV prevention intervention. Surrounded by Russia and China, countries with expanding HIV epidemics, Mongolia still has low HIV prevalence rate, estimated to be less than $0.02 \%$ among the adult population [23]. However, Mongolia currently struggles with a growing constellation of factors that may soon contribute to the regional HIV epidemic [23]. These factors include increased survival sex work among women, increased alcoholism among men and women, increased homelessness, increased migration of workers through the country, and a deteriorating health and social services system that resulted from a slow and challenging economic transition from a centrally planned to a free market economy [2326]. Such increases in sex work and migration of workers, particularly in the presence of high rates of STIs, have been associated with growing HIV epidemics across geographic boundaries on other continents [27-30]. In Mongolia, HIV cases remain clustered within high-risk groups, with $50 \%$ of all reported female HIV cases detected among women engaging in sex work, a core group interacting with key bridge populations [23]. Direct prevention intervention with women conducting sex work in Mongolia represents an opportunity to prevent a potentially rapid increase in HIV infection in urban Mongolia. Though microfinance has been one of the leading poverty reduction strategies in Mongolia [31], no microfinance programs in Mongolia specifically target women engaging in sex work, a highly stigmatized and hardto-reach population.

\section{Overview of Undarga Intervention and Pilot}

The impetus for the Undarga intervention emerged out of a prior HIV risk reduction efficacy trial with 166 women engaging in sex work in urban Mongolia. This trial demonstrated reductions of unprotected sex and harmful alcohol use among participants across all conditions, indicating that even low impact interventions can reduce risk for HIV transmission [32]. In a series of post-trial debriefing focus groups, participating women explained that while they appreciated learning risk reduction skills such as condom use and negotiation, their goals included not having to engage in sex work and gaining alternative employment. The study team developed the Undarga intervention in direct response to this feedback from prior participants. Undarga literally means in Mongolian "natural spring, fountain," or figuratively an "outflow of something good and solid; a water source; a spring of good things." The name is meant to illustrate that the program invites a new beginning for participants.
Undarga combines a multi-stage training program with a matched savings intervention. The training consists of three parts: financial literacy education, business development training, and industry-specific mentorship and support groups designed to assist women in implementing lessons learned in the trainings. In the matched savings intervention, the study team supports participating women in opening a savings account at a local bank. When participants make deposits in their saving accounts, they receive a matched amount in a parallel bank account kept on their behalf. The matched savings funds can be used for vocational education and/or business development [33]. Participants are compensated financially for attending each of the training sessions. By the end of the trainings, participants should be able to build sufficient matched savings to enter vocational training or start a small business if they save the majority of their stipends.

In 2010, the research team conducted a small pilot study for feasibility and further adaptation of the financial literacy and business development trainings, plus a shortened version of the matched savings program in which the women's savings were matched at a 1:1 ratio. Industry-specific mentorship and support groups were not included in the pilot. This paper presents the results of the Undarga pilot.

\section{METHODS}

\section{Sample Recruitment}

A purposive sample of 9 women working in sex work in Ulaanbaatar and who formerly participated in the Women's Wellness Study [32] was selected for participation. A woman was eligible for participation if she met the following criteria at screening: at least 18 years old; reported having engaged in vaginal or anal sexual intercourse in the past 90 days in exchange for money, alcohol or other goods; reported having engaged in any unprotected vaginal or anal sexual intercourse in the past 90 days with a paying, casual or "trust" sexual partner; and expressed interest in small business development. Women were invited to attend Undarga training sessions as described above, and completed process and outcome measures as described below. All protocols were reviewed and approved by both the Columbia University IRB and a local IRB at the National University of Mongolia.

\section{Intervention}

During the pilot, the team provided 12 financial literacy sessions adapted from the Microfinance Opportunities and Freedom from Hunger's Global Financial Education Program (GEFP) curriculum, which includes 5 modules: Banking Services, Savings, Budgeting, Debt Management and Financial Negotiation with partners and family members [34]. The team also facilitated 16 sessions of business development training from the International Labor Organization's (ILO) Gender and Entrepreneurship Together (GET) and Start and Improve Your Business (SIYB) trainings. GET teaches business planning, entrepreneurship, and social networking skills, while giving specific consideration to the gender-based issues that impact women's access to financial support and business opportunities [35]. SIYB is a management training curriculum that includes planning, developing, start-up, implementing and running a small business [36]. 


\section{Assessment}

Several paper-and-pencil measures were used to assess study outcomes and process. First, GFEP financial literacy pre/post-tests were administered immediately before and after completion of each of the 5 financial literacy training modules [34]. Secondly, a 20-question business development pre/post test written by the research team's business development trainer was administered immediately prior to commencing and upon completion of the business development training sessions. Third, a self-assessment was administered to provide participants an opportunity to reflect upon their personal readiness for participation in small business development. The team used an adapted version of the Microenterprise Fund for Innovation, Effectiveness, Learning and Dissemination (FIELD)'s Women's Initiative for SelfEmployment self-assessment survey [37].

Focus group discussions (FGDs) were conducted in a semi-structured format to gather participants' feedback on the implementation and design of the intervention. FGDs were held at three time points: after financial literacy sessions, immediately after the business development training sessions, and one month after the pilot ended. Additionally, at the end of each training session, a feedback form was distributed to participants asking them to indicate what they did and did not like about the session, what they did not understand about the training session, suggestions for improvement and what was the most important lesson learned [38]. In a second feedback form, facilitators were asked to describe how they perceived the participants' experiences of the sessions, including their ability to understand the content of each training session, attention to the content, the length of the session, barriers to learning, and suggestions for improving the session.

\section{Data Analysis}

Due to the small sample size, analyses were limited to simple frequencies to observe pre and post session changes among participants. Focus group discussions were transcribed and summarized by the Mongolian research team, and analyzed via thematic analysis by the research team members based in both the U.S. and Mongolia.

\section{RESULTS}

\section{Sample Description}

The sample comprised 9 women. The mean age of participants was 42 , with ages ranging from 27 to 54 . Previous educational attainment of participants varied. One participant had no formal schooling. Four participants had finished secondary school, one participant had attended some college (but had not graduated), and three participants had previously completed technical education or vocational training.

\section{Financial Literacy Knowledge Measures}

Participants demonstrated improvements in knowledge for three out of five financial literacy modules and for the business development training (see Table 1).

\section{Self-Assessment}

On a 90-point scale with 90 representing highest selfrated readiness for participation in small business development, participants rated themselves from 64 to 80, with an average score of 70 . Women consistently rated themselves highest on five points: family support of their business activities; willingness to accept financial and career risks; taking responsibility for success and failures of business; belief that they are personally responsible for success or failure; and willingness to pursue goals even when others laugh at them. The women rated themselves lowest on the following: having entrepreneurs in their family; willingness to work 50 hours or more per week; having a network of friends and acquaintances; and belief in their own skills and abilities.

\section{Daily Feedback Forms}

Participant and facilitator feedback forms indicated that women were highly engaged throughout the sessions and found the ideas stimulating, practical and relevant to their daily lives. Feedback forms emphasized that in order to maximize effectiveness in communicating with and engaging clients, the curriculum should be as participatory as possible and minimize theoretical instruction. No other significant changes were found to be necessary to the financial literacy curriculum apart from some minimal streamlining and rearranging modules to ensure proper flow of concepts. The business development training activities from Gender and Entrepreneurship Together were particularly effective since they were highly participatory, straightforward, and comprehensible. The business development training sessions from Start and Improve Your Business were, however, more difficult for participants to understand due to greater emphasis on instruction instead of activities. Feedback forms also revealed that although most participants were initially unfamiliar with business terminology used in the course, women

Table 1. Knowledge Measures

\begin{tabular}{|r|c|c|c|}
\hline & $\begin{array}{c}\text { Average Pre-Test Score } \\
(\mathbf{n = 9})\end{array}$ & $\begin{array}{c}\text { Average Post-Test Score } \\
(\mathbf{n = 9 )}\end{array}$ & Difference \\
\hline \hline Financial Literacy & & & $74 \%$ \\
\hline Banking Services & $63 \%$ & $57 \%$ & +11 \\
\hline Savings & $55 \%$ & $67 \%$ & 0 \\
\hline Budgeting & $67 \%$ & $59 \%$ & -2 \\
\hline Debt Management & $61 \%$ & $79 \%$ & +17 \\
\hline Financial Negotiations & $62 \%$ & $70 \%$ & +20 \\
\hline
\end{tabular}


learned and became comfortable with this new language throughout the course.

\section{Focus Group Themes}

Focus group discussions provided a context for a more nuanced understanding of the women's experiences participating in the financial literacy, business development trainings and matched savings, and the women's feedback on improving the intervention. All women contributed to the focus group discussions, with participation increasing over the duration of those sessions. Several consistent themes emerged from the three focus group discussions addressing women's experiences.

\section{Increased Confidence}

Women shared that the trainings helped increase confidence in themselves and hope for the future. In particular, women experienced greater confidence in negotiating with banks. Before the training, most women did not know how to navigate banking institutions and thought that "only rich people or people involved with business dealt with banks" (woman, age 42). However, by participating in the financial literacy education and communicating directly with bank representatives, the women began to feel more comfortable with banks and even felt that they could enter a bank without shame.

I used to think that banks were only for rich people. [In this training], a representative from a bank even came to see us and talked to us. This was the first time that this happened for me. I thought that someone like me could not go to a bank because you could not bring a small amount for deposit. I thought you had to bring large amounts. But now I know that even if you have a small amount, you do not need to be shy. (woman, age 39)

All the sessions were interesting. Even though all the topics are related to real life, we did not notice or know them before... For instance, before I would not feel like going to the bank to deposit 500 or 1000 tugrik. But now I know that I should not be shy because 'drops of water make a lake.' (woman, age 48)

Goal-setting exercises integrated into the financial literacy and business development trainings also resonated with the women and contributed to an increased sense of confidence. As women "started thinking about tomorrow" (woman, age 34) and set goals for their future, the women also began to see themselves differently.

I have learned that every single person has options. I thought that I was the worst person uneducated, unskilled, unwanted. But after this training, I started to trust myself and think about myself differently. This training gives not only knowledge, but gives a lot of thoughts. (woman, age 27)

I would like to say that this program has been very helpful for me. The program has exposed me to new ideas and taught me about how to set short-term and long-term goals. It has taught me to change old-fashioned ways of thinking. It has taught me that I do not have to live day-to-day, but that I can set short-term and long-term goals for myself and work towards those goals. This is a new idea for me that I appreciate very much. (woman, age 54)

\section{Changing Habitual Behavior}

Women shared that the financial literacy sessions were useful in addressing real life challenges they face with debt management, savings, and prioritization of household expenditures. Some women shared lifestyle changes they made as a result of the training, such as taking the bus instead of taking a taxi.

We learned about the family purse. Before I would spend a lot of money for nothing and I would not know about it. But when I start to write down all of my expenses I realized why my money is always gone. I now follow the tables we made during the sessions. (woman, age 42)

Women shared that putting money in their savings account helps to prevent them from spending money on unnecessary items. One woman described putting money in the bank as her strategy to "protect my money from myself!" (woman, age 48). The women also, however, reflected upon the difficulties of incorporating savings into their daily lives. Primary challenges included uneven income stream, low level of income, and balancing competing priorities such as debt payments, children's expenses, and health care needs. Additionally, one of the biggest obstacles to savings was simply getting used to putting money away in a bank account and not having immediate access to it.

The main problem is that we are not used to savings. We will always say that we will do it tomorrow. This is the biggest challenge. (woman, age 46)

The concept of the savings program is excellent, but the challenge is getting used to savings. (woman, age 42)

\section{Social Support}

Participants mentioned conflicting experiences with family and partners' support for the lessons they learned in the financial literacy training specifically. Many women shared what they learned in financial education with their children and partners at home, contributing to family members' knowledge and additional affirmation for the women from their families. Sharing lessons with their children was particularly rewarding: "This is not only for us. Through us our family members and our kids learn! They do understand these lessons as well" (woman, age 48). However, some women shared that their partners spend remaining household money on "unnecessary" items such as alcohol, candies, and cakes for children, making it difficult for women to implement lessons learned in the sessions. In light of previous literature which has documented increases in intimate partner violence (IPV) as a result of participation in microfinance programs $[39,40]$, the research team inquired whether the women's participation in the intervention contributed to IPV. None of the women reported any instances of IPV. 
Women also reported mixed experiences in the group formation process with other participants. Though women expressed a preference to start businesses in small groups rather than independently, they acknowledged they had difficulty finding common agreement with others regarding business ideas. This barrier was in part due to difficulty discerning an appropriate business idea and in part due to social dynamics between the women. Women responded favorably to a proposal from the research team to select a shortlist of industries for women to choose between (rather than leaving the industry options open-ended) and form small groups at the beginning of the business development training. Participants indicated that narrowing the industry options would help them to select group members with comparable preferences.

\section{Challenges with Savings}

Women shared that the pilot would have been more useful if the entire intervention had been piloted. With only 5 weeks of matched savings, participants did not have sufficient time to "combine theory with practice" (women, age 42) and build adequate matched savings to reach their vocational goals. In addition to time limitations, women struggled with adapting to the habit of regular savings. As one woman aged 42 said "we always think to put money away, but think that we will do it tomorrow." The difficulty in reaching savings goals caused stress for some participants. One woman said she felt more stress after the trainings because she believed for the first time that she has options for the future. She never considered before that there were alternatives to sex work, and she feels stressed until her new goals can be realized.

This training has given me a lot of new knowledge. I have learned so much. I now know that I have other opportunities and this creates pressure. My options are limited, which makes me feel stress. I know that I need savings for unexpected expenses, but I do not have good marketable skills. This makes me feel pressure. I am eager to do something, but I need vocational support. If I did not know any of these things, it would be easier for me. Even though this new knowledge brings stress, I am still very glad that $I$ joined this training and appreciate all of the things I have learned. (woman, age 46)

Additionally, women expressed the need for an alternative income source from which to build their savings, which was in fact the idea underlying the intervention. In the pilot, women were provided stipends for participating in every training session. These stipends were intended to be used as an additional income source, from which women could build their savings. However, women did not perceive the stipends as income and in fact, often took their stipends for consumption purposes.

Some of us leave the sessions with our payment. When we leave, that money is in our hands. If we take it out with us, we will no doubt spend it on something unnecessary. I think we need put away money as far as we can - so far that we cannot reach it. (woman, age 46)

During the pilot, women shared the idea to develop a contract with program staff to place a portion of their stipends into savings after each session. However, when this option was offered in practice, participants selected not to do so.

\section{Alternative Employment Outcomes}

Though the limited version of this pilot only provided 5 weeks of the matched savings program and did not provide industry support group sessions, a three-month follow-up by program staff revealed that several participants changed their employment strategies. The woman profiled immediately above (age 46) secured a full-time job working as a domestic worker and has reported leaving sex work. A second participant (age 42) has secured two jobs - one as a security guard and a second job as an outreach worker providing HIV and STI prevention education. One woman (aged 27) reported that she has separated herself from her pimp, is living in a shelter, and participating in sewing and literacy classes. One woman (aged 54) has started a small enterprise selling food, which is expected to be seasonal, and another woman (aged 39 ) is continuing in sex work while she plans to start a small business. One participant (aged 42) is continuing sex work at reduced hours until she commences a wool craft training course shortly. One woman (aged 49) was unable to secure alternative employment and continues in sex work as before. The research team was unable to reach two women (aged 34 and 48).

\section{DISCUSSION}

Findings from this pilot suggest the feasibility of combining a savings-led microfinance intervention with an HIV sexual risk reduction program for women conducting sex work in Mongolia. Women indicated that the pilot helped build their confidence in their ability to manage finances, and gave them hope for pursuing their short-term and longterm goals. Women demonstrated moderate knowledge gains in banking services, savings, financial negotiations, and small business development. Through their own initiative, at least five participants reduced their hours in sex work to pursue alternative employment, vocational training, or small business start-up. Given that the entire microfinance intervention was not piloted and that only five weeks were provided for matched savings, these changes are notable.

Pilot findings highlight several key areas for improving the microfinance component of the intervention. First, we adapted training materials to ensure cultural relevance and foster interaction. Whereas the financial literacy curriculum needs minimal adaptation, the team removed most of the business development activities from the Start Your Business curriculum, which were not interactive, keeping the more participatory Gender and Entrepreneurship Together curriculum. More active, visual exercises replaced theoretical, didactic exercises to engage the entire group. Secondly, we revised assessment questions to better reflect the content covered in the training sessions, to target the appropriate difficulty level, and to ensure clear wording of questions post-translation. Third, feedback gained from the pilot confirmed the research team's inclination to select a shortlist of 
three industries for the women to choose between for vocational training/small business development and to incorporate interest in these industries into program eligibility criteria. Though this approach may risk reducing women's ownership over their vocational decisions, it is evident from the pilot that this direction is initially necessary to help participants focus and move toward achievable goals. Fourth, the research team concluded that, along with industry selection, small business group formation should occur at the beginning of business development training in order to foster group cohesion and enable the women to apply all lessons learned in business development training to their respective business ideas.

The pilot experience taught the research team that messaging and presentation of a savings program may be as influential as the economic incentives for participation [41]. If training sessions are presented as a part-time job for which participants will receive a salary, they may be more inclined to see the payments as an alternative income source. Though the research team could withhold part of the incentive payments and place it directly in the women's savings accounts, we are still inclined to have the women choose for themselves whether or not to deposit their money in their accounts. Although this approach may slow down the accumulation of savings in the short-term, it provides the women with more ownership and opportunity to practice savings themselves in a supportive group context. To facilitate this process, we will incorporate more regular goal-setting activities in the beginning of each financial literacy and business development session to check in with participants regarding their progress toward individualized savings goals. To further support participants in building sufficient matched savings for both vocational education and business start-up expenses, we will increase the savings match from a 1:1 to a 2:1 match. A 2:1 match has been demonstrated to be more effective in facilitating asset development than a 1:1 match in previous studies [42].

Study findings, however, need to be considered in light of several limitations. First the pilot sample was nonrepresentative, preventing generalization of results to women engaging in sex work in Ulaanbaatar. Industry-specific mentorship groups were not piloted, resulting in the women missing an opportunity to integrate lessons learned in an applied context with social support. Only 5 weeks were provided for women to participate in the matched savings program. A longer pilot would have enabled participants to build a greater amount in their matched savings, thereby providing more options for vocational training and small business development.

An additional limitation of the proposed intervention is the focus on traditionally female industries. We decided to target the wool craft and quilting industries, both of which are considered traditionally 'female' industries. One critique of microcredit has been that it tracks women into lowearning, home-based enterprises, in part by failing to explicitly support with market access and diversification outside traditionally 'female' industries [20, 21]. In very competitive or oversaturated markets, stigmatized women with smaller social networks may be at a disadvantage when competing with more established enterprises [21], perhaps compelling women to engage in more survival sex work. However, both business partners we selected provide vocational training programs and agree to buy products made by training graduates as long as products meet quality control standards. We anticipate that these market linkages may lessen some of the disadvantages women engaging in sex work may face in these industries.

Another potential concern is that of sustainability of the matched savings component of the intervention. While matched savings programs contain numerous advantages including security of savings, high returns and ease of access to savings - they are not as financially sustainable as creditbased microfinance alternatives [22]. If the Undarga project is demonstrated feasible in the current funded study, researchers will work with foundations and local advisors to identify donors most appropriate to subsidize or support the matched savings intervention for this target population.

Finally, in this pilot we did not monitor use of alcohol by participants. Based on screening data from our prior study, we know that among women engaging in sex work in Ulaanbaatar, up to $90 \%$ use alcohol at harmful levels. We also know from facilitator anecdotes that some women in this pilot attended some sessions under the influence of alcohol. Alcohol use will be an important moderator in a planned larger scale implementation of this intervention. The next step in our research will be to conduct feasibility testing on the entire intervention, combining the revised microfinance intervention with the HIV-sexual risk reduction sessions, which was already proven to be effective in reducing unprotected sex and harmful alcohol use for women in engaging in sex work in Ulaanbaatar [32]. In an upcoming project, a 2arm randomized clinical trial design will allow us to explore feasibility of the combined HIV risk reduction and microfinance intervention with a larger group of women conducting sex work, and to establish preliminary effect sizes for outcomes, including HIV/STI sexual risk behaviors and increases in proportions of income not from sex work, at 3 and 6 months post-intervention.

Findings from this pilot study and the upcoming clinical trial testing the efficacy of the microfinance program respond to the call for more rigorous testing of economic empowerment interventions to address HIV risk reduction. Development and testing of the combination of microfinance components may lead to sustainable change, providing skills and knowledge that may be generalized across industries, offering an opportunity for more flexibility in becoming economically self-sufficient. The groundwork described and the proposed study which builds on it may have significant potential impact, as it tests a structural model to reduce sexual risk among women engaging in sex work in a low income country, which may advance the gender-specific prevention repertoire for women at increased risk for HIV and STIs globally.

\section{CONFLICT OF INTEREST}

\section{None declared.}

\section{ACKNOWLEDGEMENT}

This study was supported by the Global Health Research Center of Central Asia (GHRCCA), Columbia University, and NIMH grant \#R34MH093227 awarded to Dr. Witte. 


\section{REFERENCES}

[1] Dworkin SL, Blankenship K. Microfinance and HIV/AIDS prevention: assessing its promise and limitations. AIDS Behav 2009; 13(3): 462-9

[2] Exner T, Hoffman S, Dworkin S, Ehrhardt A. Beyond the male condom: the evolution of gender-specific HIV interventions for women. Annu Rev Sex Res 2003; 14: 113-46.

[3] Grieg FE, Koopman C. Multilevel analysis of women's empowerment and HIV prevention: quantitative survey results from a preliminary study in Botswana. AIDS Behav 2003; (7): 195208

[4] Hallman K. Socioeconomic disadvantage and unsafe sexual behaviors among young women and men in South Africa. Policy research division working paper no. 190. New York, Population Council. 2004

[5] Odek W, Busza J, Morris C, Cleland J, Ngugi E, Ferguson A. Effects of micro-enterprise services on HIV risk behaviour among female sex workers in Kenya's urban slums. AIDS Behav 2009; 13(3): 449-61.

[6] Sherman S, German D, Cheng Y, Marks M, Bailey-Kloche M. The evaluation of the JEWEL project: an innovative economic enhancement and HIV prevention intervention study targeting drug using women involved in prostitution. AIDS Care 2006: 18(1): 111.

[7] Stratford D, Mizuno Y, Williams K, Courtenay-Quirk C, O'Leary A. Addressing poverty as risk for disease: recommendations from CDC's consultation on microenterprise as HIV prevention. Public Health Rep 2008; 123: 9-18

[8] Gupta G, Parkhurst J, Ogden J, Aggleton P, Mahal A. Structural approaches to HIV prevention. Lancet 2008: 372(9640): 764-75.

[9] Kim J, Pronyk P, Barnett T, Watts C. Exploring the role of economic empowerment in HIV prevention. AIDS 2008; 22(Suppl 4): S57-S71

[10] Kim J, Watts C. Gaining a foothold: tackling poverty, gender inequality, and HIV in Africa. BMJ 2005; 331(7519): 769-72.

[11] Parker R, Easton D, Klein C. Structural barriers and facilitators in HIV prevention: a review of international research. AIDS 2000; 14: 22-32.

[12] Sumartojo E. Structural factors in HIV prevention: concepts, examples, and implications for research. AIDS 2000; 14: S3-10.

[13] Pronyk P, Kim J, Hargreaves J, et al. Microfinance and HIV prevention-emerging lessons from rural South Africa. Small Enterprise Devel 2005; 16(3): 26-38.

[14] Parker J, Singh I, Hattel K. The role of microfinance in the fight against HIV/AIDS: The Joint United Nations Program on HIV/AIDS (UNAIDS) 2000.

[15] Pronyk PM, Kim JC, Abramsky T, et al. A combined microfinance and training intervention can reduce HIV risk behavior in young female participants. AIDS 2008; 22: 1659-65.

[16] Pronyk P, Hargreaves J, Kim J, et al. Effect of a structural intervention for the prevention of intimate-partner violence and HIV in rural South Africa: a cluster randomized trial. Lancet 2006; 368(9551): 1973-83

[17] Sherman SG, Srikrishnan AK, Rivett KA, Liu S-H, Solomon S, Celentano DD. Acceptability of a microenterprise intervention among female sex workers in Chennai, India. AIDS Behav 2010; 14: $549-657$

[18] Fiebig M, Hannig A, Wisniwski S. Savings in the context of microfinance-state of knowledge. Working Group on Savings Mobilization. Eschborn, Germany: GTZ and CGAP. 1999.

[19] Brett JA. We sacrifice and eat less: the structural complexities of microfinance participation. Hum Organ 2006: 65(1): 8-19.

[20] Milgram BL. Operationalizing microfinance: women and craftwork in Ifugao, Upland Philippines. Hum Organ 2001; 60(3): 212-24.
[21] Mayoux L. Questioning virtuous spirals: micro-finance and women's empowerment in Africa. J Int Dev 1999; 11(7): 957-84

[22] Vonderlack RM, Schreiner M. Women, microfinance, and savings: lessons and proposals. Dev Pract 2002; 12(5): 602-12.

[23] UNGASS. UNGASS country progress report: Mongolia. New York, NY, United Nations General Assembly. 2010.

[24] NAF. Summary of review and evaluation of STI/HIV/AIDS community projects implemented by NGOs/CBOs in 2003. Ulaanbaatar: National AIDS Foundation 2003.

[25] Purevdawa E, Moon T, Baigalmaa C, Davaajav K, Smith M, Vermund S. Rise in sexually transmitted diseases during democratization and economic crisis in Mongolia. Int J STD AIDS 1997; 8(6): 398-401

[26] NAF. HIV and drug use participatory situation assessment report. Ulaanbaatar, Mongolia: NAF/UNDCP/HIV Alliance. 2001.

[27] Fages V. Migration and AIDS in South Africa: A public health issue. Pretoria: UNAIDS. 1999.

[28] UNAIDS. Population mobility and AIDS - technical update. Geneva: United Nations. 2001

[29] UNAIDS. Sex Work and HIV/AIDS - technical report. Geneva: United Nations 2002.

[30] Ghys PD, Jenkins C, Pisani E. HIV surveillance among female sex workers. AIDS 2001; 15 (Suppl 3): S33-40.

[31] UNCDF (United Nationals Capital Development Fund). Report from the field: microfinance plays strong role in Mongolia's poverty reduction strategy $2005 ; 16: 26-9$.

[32] Witte SS, Altantsetseg B, Aira T, et al. Reducing sexual HIV/STI risk and harmful alcohol use among sex workers in Mongolia: A randomized clinical trial. AIDS Behav 2011; 15: 1785-94.

[33] Sherraden M. Assets and the poor: a new American welfare policy. Armonk, NY; ME Sharpe, Inc; 1991.

[34] Microfinance Opportunities \& Freedom from Hunger. Global Financial Education Program. Retrieved from http: //www.globalfinancialed.org/curriculum.html. [Accessed on March 18, 2010].

[35] ILO. Small Enterprise Development Programme WED Fact Sheet 3. Geneva, Switzerland, International Labor Organization. 2009. Retrieved from http: //www.ilo.org/wcmsp5/groups/public/-ed_emp/---emp_ent/---ifp_seed/documents/publication/wcms 111368.pdf. [Accessed on March 18, 2010].

[36] ILO. Job Creation and Enterprise Development Department Small Enterprise Development program SIYB Fact Sheet. 2009. Retrieved from http: //bravo.ilo.org/wcmsp5/groups/public/---ed_emp/ ---emp_ent/documents/publication/wcms_101309.pdf. [Accessed on March 18, 2010].

[37] Klein J. Entering the relationship: finding and assessing microenterprise training clients. Microenterprise Fund for Innovation, Effectiveness, Learning and Dissemination (FIELD) best practice guild: volume 1. 2002. Available at: http: //www.fieldus.org/ Publications/PrimeVoll.pdf. [Accessed March 20, 2010].

[38] ILO. The daily reaction evaluation form. Available at http: //www.ilosiyb.co.zw/siyb_forms.html. [Accessed March 15, 2010].

[39] Jewkes, R. Intimate partner violence: causes and prevention. Lancet 2002; 359: 1423-9.

[40] Schuler RS, Hashemi SM,Badal SH. Men's violence against women in rural Bangladesh: undermined or exacerbated by microcredit programmes? Dev Pract 1998; 8(2): 148-57.

[41] Karlan D, Morduch, J. Access to finance: ideas and evidence the economics of savings. 2009. Available at http: //www.microfinancegateway.org/gm/document-1.1.4302/The\%20Economics\% 20of\%20Saving.pdf. [Accessed February 4, 2010].

[42] Ssewamala FM, Sherraden M. Integrating saving into microenterprise programs for the poor: do institutions matter? Soc Serv Rev 2004; 78: 404-28. (http://creativecommons.org/licenses/by-nc/3.0/) which permits unrestricted, non-commercial use, distribution and reproduction in any medium, provided the work is properly cited. 